\title{
Irinotecan plus carboplatin for patients with carcinoma of unknown primary site
}

\section{K Yonemori*,', M Ando', M Yunokawa', T Hirata', T Kouno', C Shimizu', K Tamura', N Katsumata', A Hirakawa ${ }^{2}$, K Matsumoto ${ }^{1,3}$, Y Yamanaka ${ }^{1,4}$, H Arioka ${ }^{5}$ and Y Fujiwara'}

'Breast and Medical Oncology Division, National Cancer Center Hospital, 5-I I Tsukiji, Chuo-ku, Tokyo 104-0045, Japan; ${ }^{2}$ Department of Management Science, Graduate School of Engineering, Tokyo University of Science, I-3 Kagurazaka, Shinjuku-ku, Tokyo I 62-860 I, Japan; ${ }^{3}$ Medical Oncology Division, Hyogo Cancer Center, 13-70 Kitaouji-cho, Akasi, Hyogo 673-8558, Japan; ${ }^{4}$ Medical Oncology Division, Tochigi Cancer Center, 4-9-I 3 Yonan,

Utsunomiya, Tochigi 320-0834, Japan; ${ }^{5}$ Medical Oncology Division, Yokohama Rosai Hospital, 321 I Kozukue, Kohoku-ku, Yokohama, Kanagawa 222-0036, Japan

Carcinoma of unknown primary site (CUP) is rarely encountered in clinical practice and optimal chemotherapy has not yet been established. This phase II study was conducted to evaluate the efficacy and toxicity of combined irinotecan + carboplatin therapy in chemotherapy-naive patients with CUP. Irinotecan was administered at $60 \mathrm{mg} \mathrm{m}^{-2}$ as a 90-min intravenous infusion on days I, 8 and 15. Carboplatin was administered at an area-under-the curve of $5 \mathrm{mg} \mathrm{ml}^{-1} \mathrm{~min}$ as a $60-\mathrm{min}$ intravenous infusion on day I. This cycle was repeated every 28 days for up to six cycles. Forty-five patients were enrolled in the study. An intent-to-treat analysis revealed an objective response rate to the treatment of $41.9 \%$ (95\% confidence interval, $27.0-57.9 \%$ ). The median time to progression was 4.8 months and the median survival was 12.2 months. The I- and 2-year survival rates were 44 and $27 \%$, respectively. The most frequent grade 3 or more severe adverse events were leukopaenia (21\%), neutropaenia (33\%), anaemia (25\%) and thrombocytopaenia (20\%). Thus, the combination of irinotecan plus carboplatin was found to be active in patients with CUP. Therefore, the regimen may be one of the potentially available chemotherapeutic options for community standard of care in patients with a good performance status. British Journal of Cancer (2009) I 00, 50-55. doi: I0.1038/sj.bjc.6604829 www.bjcancer.com

Published online 16 December 2008

(c) 2009 Cancer Research UK

Keywords: carboplatin; chemotherapy; irinotecan; unknown primary

Carcinoma of unknown primary site (CUP) represents a group of heterogeneous malignancies that is diagnosed based on the presence of a metastatic disease without an identifiable primary tumour at the time of presentation. Carcinoma of unknown primary site accounts for approximately $3-5 \%$ of all newly diagnosed patients with malignancies (Briasoulis et al, 2008b).

The prognosis of CUP is generally poor, with a median overall survival time (OS) of approximately 6-12 months. Some of these patients with favourable and unique clinical and/or pathologic features may show prolonged survival with specific treatment approaches (Pavlidis et al, 2003). However, most of the patients fit into the category of poor prognosis. Many investigators have made efforts to develop optimal chemotherapeutic regimens based on the empiric approach, and platinum-based combination chemotherapy is considered to be one of the suitable treatment options for a large proportion of these patients (Pavlidis et al, 2003).

Irinotecan is a potent inhibitor of DNA topoisomerase I. It exhibits excellent antitumour activity, not only against a broad spectrum of tumours in experimental models (Kano et al, 1992; Misawa et al, 1995). Carboplatin is an analogue of cisplatin, with less severe non-haematological toxicities (Briasoulis et al, 2000; Yonemori et al, 2005). No cross-resistance has been found between irinotecan and carboplatin, and a synergistic effect of irinotecan

*Correspondence: Dr K Yonemori; E-mail: kyonemor@ncc.go.jp Revised 3 November 2008; accepted 21 November 2008; published online 16 December 2008 with carboplatin has been shown in in vitro studies (Kano et al, 1993).

In an earlier study conducted by us, although the combination of docetaxel plus cisplatin produced favourable results in patients with CUP, treatment discontinuation sometimes became necessary because of the renal toxicity induced by cisplatin (Mukai et al, 2003; Yakushiji et al, 2006). Carboplatin has proven to be as effective as cisplatin against chemosensitive CUP, with an additional advantage of being better tolerated and more convenient in clinical practice (Briasoulis et al, 2000). In this study, we report the results of a phase II trial conducted to evaluate the effect of irinotecan plus carboplatin in the treatment for CUP.

\section{PATIENTS AND METHODS}

\section{Patients}

Patients who had histologically confirmed metastatic carcinoma were eligible for enrollment in this study, if the following evaluations did not reveal a primary site: complete history, physical examination, blood counts and blood chemistry examinations, including serum $\alpha$-fetoprotein (AFP) and $\beta$-human chorionic gonadotropin ( $\beta$-HCG) as tumour markers in both sexes, carbohydrate antigen 125 (CA125) as a tumour marker in women, prostate-specific antigen (PSA) as a tumour marker in men, urinalysis, head and neck examination with pharyngeal 
endoscopy conducted by experienced head and neck surgeons, urologic examination conducted by experienced urologists, mammography in women, gynaecologic examination by experienced gynaecologists in women, chest X-ray, whole-body computed tomography, upper gastrointestinal endoscopy, lower gastrointestinal endoscopy or barium enema, bone scintigraphy and direct workup of any symptomatic area.

Patients were enrolled in the study if they fulfilled the following eligibility criteria: (1) diagnosed as having CUP, (2) chemotherapy naive, (3) age $\geqslant 20$ years, (4) life expectancy of at least 3 months, (5) an Eastern Cooperative Oncology Group performance status of $\leqslant 2$, (6) the presence of a measurable lesion as assessed by Response Evaluation Criteria in Solid Tumors (RECIST) (Therasse et $a l, 2000$ ) and (7) adequate organ function (total leukocyte count $\geqslant 3000$ per $\mu \mathrm{l}$ or absolute neutrophil count $\geqslant 1500$ per $\mu \mathrm{l}$, platelet count $\geqslant 100000$ per $\mu \mathrm{l}$, serum total bilirubin $\leqslant 1.5 \mathrm{mg} \mathrm{dl}^{-1}$, serum alanine aminotransferase $\leqslant 2$ times the upper limit of normal, serum creatinine $\leqslant 1.5 \mathrm{mg} \mathrm{dl}^{-1}$ ). Patients with active infection, bowel obstruction, interstitial pneumonitis, uncontrolled severe heart disease, uncontrolled diabetes mellitus, pregnant or lactating women, symptomatic brain metastasis, severe coexistent medical illness or a past history of hypersensitivity to drugs were excluded from the study. Patients who had massive pleural effusion or ascites that required drainage or active concomitant malignancy were also excluded. Patient subgroups that were suitable for well-established treatments (i.e., men with blastic bone metastases showing features of adenocarcinoma and elevated PSA, women with axillary lymph nodes as the only site of disease showing features of adenocarcinoma, woman with papillary serous carcinoma of the peritoneum, patients with either cervical or inguinal lymph node involvement only with features of squamous cell carcinoma, patients with poorly differentiated carcinomas suggestive of germ cell tumour with elevated levels of AFP and/or $\beta$-HCG, patients with low-grade, well-differentiated neuroendocrine carcinoma and patients with carcinoma involving a single, potentially resectable site) were also excluded from the study. The protocol was approved by the institutional review board. All patients provided written informed consent before their enrollment.

\section{Treatment}

Irinotecan was administered at the dose of $60 \mathrm{mg} \mathrm{m}^{-2}$ dissolved in $100 \mathrm{ml}$ saline as a 90-min intravenous infusion, followed by carboplatin at an area-under-the curve of $5 \mathrm{mg} \mathrm{ml}^{-1}$ min dissolved in $250 \mathrm{ml}$ of saline or $5 \%$ dextrose as a 60 -min intravenous infusion. Irinotecan administration was planned for days 1, 8 and 15 of each cycle, and that of carboplatin was planned for day 1 of each cycle. The Calvert formula was used to determine the carboplatin dose, based on the glomerular filtration rate calculated using the serum creatinine level, body weight, age and sex (Cockcroft and Gault, 1976; Calvert et al, 1989). Patients showing treatment response or stable disease were administered up to a total of six courses. Granisetron $3 \mathrm{mg}$ and dexamethasone $8 \mathrm{mg}$ were used routinely before the drug infusions as antiemetic agents on days 1, 8 and 15. Prophylactic granulocyte colony-stimulating factor was not used routinely.

Irinotecan and carboplatin were administered on day 1 if the leukocyte count was $\geqslant 3000$ per $\mu$ l or the neutrophil count was $\geqslant 1500$ per $\mu \mathrm{l}$, the platelet count was $\geqslant 75000$ per $\mu \mathrm{l}$, serum total bilirubin was $\leqslant 1.5 \mathrm{mg} \mathrm{dl}^{-1}$, serum alanine aminotransferase was $\leqslant 2$ times the upper limit of normal, the serum creatinine was $\leqslant 1.5 \mathrm{mg} \mathrm{dl}^{-1}$ and any non-haematological toxicities, with the exception of alopaecia, were $\leqslant$ grade 1 . Patients who failed to improve to less than grade 2 in terms of the non-haematological toxicity even after withholding of the treatment for 2 weeks were withdrawn from the study.
Irinotecan was administered on day 8 or 15 if the leukocyte count was $\geqslant 2000$ per $\mu$ l or the neutrophil count was $\geqslant 1000$ per $\mu$ l, the platelet count was $\geqslant 75000$ per $\mu \mathrm{l}$ and any non-haematological toxicities, with the exception of alopaecia, were $\leqslant$ grade 1 . The dose on day 8 and/or day 15 was omitted entirely if the counts or toxicities did not satisfy the above criteria.

Dose modification of carboplatin from AUC 4 to AUC 5 was allowed if febrile neutropaenia or grade 4 thrombocytopaenia was observed, or if platelet transfusion was required.

\section{Response and toxicity evaluation}

All patients were re-evaluated for response after completion of two cycles of treatment, and the response categories were assigned based on the RECIST criteria (Therasse et al, 2000). Repeat scans at 8-week intervals were performed to confirm the response. The final response category assigned to these patients represented the best response obtained during the treatment course. Toxicities were evaluated according to the National Cancer Institute's Common Toxicity Criteria, Version 2.0, after every cycle and at the end of the study treatment.

\section{Statistical analysis}

The primary end point of this study was the objective response rate, defined as the proportion of patients with complete response or partial response in the intent-to-treat (ITT) population, in turn, defined as patients who had received at least one cycle of irinotecan and carboplatin. The secondary end points included safety and tolerability, time to tumour progression (TTP), OS, and the 1- and 2-year survival rates.

The sample size was determined using Simon's Minimax two-stage design for phase II studies. The response rates to chemotherapy of patients with CUP have been reported as approximately in the range of $20-40 \%$ (Briasoulis et al, 2000; Greco et al, 2000a, b; Dowell et al, 2001), so that the null hypothesis was that the true response rate was less than or equal to $30 \%$ (not considered to be clinically meaningful). The alternative hypothesis was that the true response rate was more than or equal to $50 \%$. A total of 39 patients were required as the target sample to ensure results with $80 \%$ power and a type I error rate of $5 \%$, for rejecting the null hypothesis that the true response probability was less than or equal to $30 \%$. The enrollment of 45 patients was planned to fulfill the requirement of 39 patients, because some patients might need to be potentially excluded from the analysis because of failure to receive at least one cycle of irinotecan and carboplatin.

The objective response rate was reported as a percentage, along with the $95 \%$ confidence interval. The TTP and OS were determined by the Kaplan-Meier method. All the statistical analyses were performed using SPSS 12.0J (SPSS Inc., Chicago, IL, USA).

\section{RESULTS}

\section{Patient characteristics}

Between May 2003 and November 2007, 45 patients were enrolled in this clinical trial. The patient characteristics are listed in Table 1. The median age was 59 years (range, $36-78$ years), and the median performance status (PS) was 1 (range, $0-2$ ). The median number of disease sites per patient was two (range, 1-7).

Twenty-three patients had lymph node involvement only. Serum tumour markers were assessed at the baseline pretreatment evaluation in 43 patients. The median number of tumour markers showing elevated serum levels was 5 (range, $0-10$ ). Eighty-seven percent $(N=39)$ of the patients showed elevated serum levels of tumour markers at the time of diagnosis (Table 2). 
Table I Patient characteristics

\begin{tabular}{|c|c|}
\hline Characteristics & No. of patients \\
\hline No. of patients enrolled & 45 \\
\hline \multicolumn{2}{|l|}{ Age (years) } \\
\hline Median & 59 \\
\hline Range & $36-78$ \\
\hline \multicolumn{2}{|l|}{ Sex } \\
\hline Male & 23 \\
\hline Female & 22 \\
\hline \multicolumn{2}{|l|}{ ECOG performance status } \\
\hline 0 & 19 \\
\hline । & 22 \\
\hline 2 & 4 \\
\hline \multicolumn{2}{|l|}{ Histologic type } \\
\hline Adenocarcinoma (well and moderately differentiated) & 21 \\
\hline Poorly differentiated adenocarcinoma & 9 \\
\hline Squamous cell carcinoma & 7 \\
\hline Poorly differentiated carcinoma & 5 \\
\hline Clear cell carcinoma & I \\
\hline Small cell carcinoma & I \\
\hline Undifferentiated carcinoma & । \\
\hline \multicolumn{2}{|l|}{ No. of disease sites } \\
\hline । & 13 \\
\hline 2 & 10 \\
\hline$\geqslant 3$ & 22 \\
\hline \multicolumn{2}{|l|}{ Site of disease } \\
\hline Lymph node & 40 \\
\hline Lung & 6 \\
\hline Bone & 4 \\
\hline Liver & 8 \\
\hline Adrenal & 2 \\
\hline Malignant effusion & 4 \\
\hline Soft tissue & 3 \\
\hline Other & 6 \\
\hline \multicolumn{2}{|l|}{ Prognostic index } \\
\hline \multicolumn{2}{|l|}{ Culine et al $(2002 a)^{a}$} \\
\hline Good risk & 29 \\
\hline Poor risk & 16 \\
\hline \multicolumn{2}{|l|}{ van der Gaast et al $(1996)^{b}$} \\
\hline Good risk & 19 \\
\hline Intermediate risk & 19 \\
\hline Poor risk & 7 \\
\hline
\end{tabular}

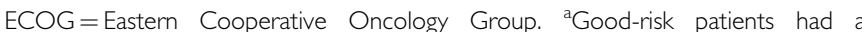
performance status of 0 or I and normal serum lactate dehydrogenase (LDH) levels; poor-risk patients had a performance status of $\geqslant 2$ or elevated serum LDH levels. ${ }^{b}$ Good-risk patients had a performance status of 0 and serum alkaline phosphatase (ALP) levels of $<1.25 \times$ normal range $(N)$; intermediate-risk patients had a performance status of $\geqslant 1$ or serum ALP levels of $\geqslant 1.25 \times N$; poor-risk patients had a performance status of $\geqslant 1$ and serum ALP levels of $\geqslant 1.25 \times \mathrm{N}$.

\section{Efficacy}

Forty-five patients were enrolled in this study. All the enrolled patients were included in the analysis for TTP and OS, and 43 patients who had received at least one cycle of irinotecan plus carboplatin were assessed for tumour response to treatment. Two patients who were withdrawn from the study because of the appearance of toxicity in cycle 1 were considered as not evaluable. Objective response was observed in 18 patients, including complete response in two and partial response in 16 patients. Stable disease was observed in 10 patients and progressive disease in 15 patients. The results of an ITT analysis revealed an objective
Table 2 Elevated serum tumour marker levels at diagnosis

\begin{tabular}{|c|c|c|c|}
\hline Markers & $\begin{array}{l}\text { Normal } \\
\text { range }\end{array}$ & $\begin{array}{l}\text { No. of measured } \\
\text { patients }\end{array}$ & $\begin{array}{c}\text { No. of } \\
\text { patients with } \\
\text { elevated levels (\%) }\end{array}$ \\
\hline AFP & $\leqslant 10 \mathrm{ng} \mathrm{ml}^{-1}$ & 42 & $2(4.7)$ \\
\hline$\beta$-HCG & $\leqslant 0.5 \mathrm{mlU} \mathrm{ml}^{-1}$ & 42 & $22(52.4)$ \\
\hline Cyfra & $\leqslant 2.2 \mathrm{ng} \mathrm{ml}^{-1}$ & 41 & $30(73.2)$ \\
\hline SCC & $\leqslant 1.5 \mathrm{ng} \mathrm{ml}^{-1}$ & 41 & $7(17.1)$ \\
\hline NSE & $\leqslant 15 \mathrm{ng} \mathrm{ml}^{-1}$ & 42 & $10(23.8)$ \\
\hline ProGRP & $<46 \mathrm{pg} \mathrm{ml}^{-1}$ & 41 & $8(19.5)$ \\
\hline PSA & $\leqslant 2.7 \mathrm{ng} \mathrm{ml}^{-1}$ & 23 & $5(21.7)$ \\
\hline CEA & $\leqslant 5.0 \mathrm{ng} \mathrm{ml}^{-1}$ & 43 & $19(44.2)$ \\
\hline SLX & $\leqslant 38 \cup \mathrm{ml}^{-1}$ & 41 & $21(51.2)$ \\
\hline STN & $\leqslant 45 \cup \mathrm{ml}^{-1}$ & 41 & $16(39)$ \\
\hline NCC-ST439 & $\leqslant 4.5 \cup \mathrm{ml}^{-1}$ & 41 & 16 (39) \\
\hline CAI25 & $\leqslant 35 \cup \mathrm{ml}^{-1}$ & 39 & $25(64.1)$ \\
\hline CAI5-3 & $\leqslant 28 \cup \mathrm{ml}^{-1}$ & 41 & $12(29.3)$ \\
\hline CAI9-9 & $\leqslant 37 \cup \mathrm{ml}^{-1}$ & 43 & $17(39.5)$ \\
\hline PIVKA-II & $<40 \mathrm{mlU} \mathrm{ml}^{-1}$ & 39 & $2(5.1)$ \\
\hline Elastase & $\leqslant 300 \mathrm{ng} \mathrm{dl}^{-1}$ & 41 & $3(7.3)$ \\
\hline
\end{tabular}

AFP $=\alpha$-fetoprotein; CAI25 = carbohydrate antigen 125; CAI5-3= carbohydrate antigen 15-3; CA19-9= carbohydrate antigen 19-9; CEA = carcinoembryonic antigen; Cyfra = cytokeratin 19 fragment; NCC-ST439= national cancer centerST439; NSE = neuron-specific antigen; PIVKA- II = protein induced by vitamin $\mathrm{K}$ absence-2; ProGRP = progastrin-releasing peptide; PSA = prostate-specific antigen SCC = squamous-cell carcinoma antigen; $\mathrm{SLX}=$ sialyl-specific embryonic antigen; $\mathrm{STN}=$ sialyl TN antigen; $\beta$-HCG $=\beta$-human chorionic gonadotropin

response rate of $41.9 \%$ ( $95 \%$ confidence interval, $27.0-57.9 \%)$; the response rate was $41.3 \%$ in the 30 patients with well-to-poorly differentiated adenocarcinoma and $50.0 \%$ in the 23 patients with lymph node involvement only. The median TTP was 4.8 months, and the median OS was 12.2 months. The 1- and 2-year survival rates were 44 and $27 \%$, respectively (Figure 1).

\section{Toxicity}

The toxicity data are listed in Table 3. Bone marrow suppression (leukopaenia, neutropaenia and thrombocytopaenia) and gastrointestinal toxicities, such as nausea, vomiting, diarrhoea and appetite loss, were the most frequent. There were no treatmentrelated deaths in this study.

Overall, 180 treatment cycles were administered and the median number of cycles per patient was four (range, 1-6). Of the 180 cycles, in $9.4 \%$ (17 episodes), the day-8 administration of irinotecan was withheld because of neutropaenia (11.8\%), anaemia (5.9\%), thrombocytopaenia $(35.3 \%)$ or non-haematological toxicity $(41.1 \%)$, including two episodes of fatigue, three episodes of nausea, two episodes of infection and one episode of palpitation. Furthermore, in $27.2 \%$ of the cycles, the day-15 administration of irinotecan was withheld because of neutropaenia $(14.3 \%)$, thrombocytopaenia (65.3\%), non-haematological toxicity $(16.3 \%)$, including one episode of appetite loss, one episode of nausea, two episodes of diarrhoea, four episodes of febrile neutropaenia and patient refusal for personal reasons (two instances). The day- 8 or day-15 irinotecan was withheld at least once in 24 (53\%) patients. Five patients $(11.1 \%)$ with anaemia required red blood cell transfusion and four patients (8.9\%) with thrombocytopaenia required platelet transfusion. Dose modification of carboplatin was necessary in $15.5 \%$ of the patients (seven patients).

\section{DISCUSSION}

Recently published trials, in the literature, of regimens containing platinum agents for CUP have reported objective response rates in the range of $13-55 \%$ and median OS in the range of $6.0-16.2$ 


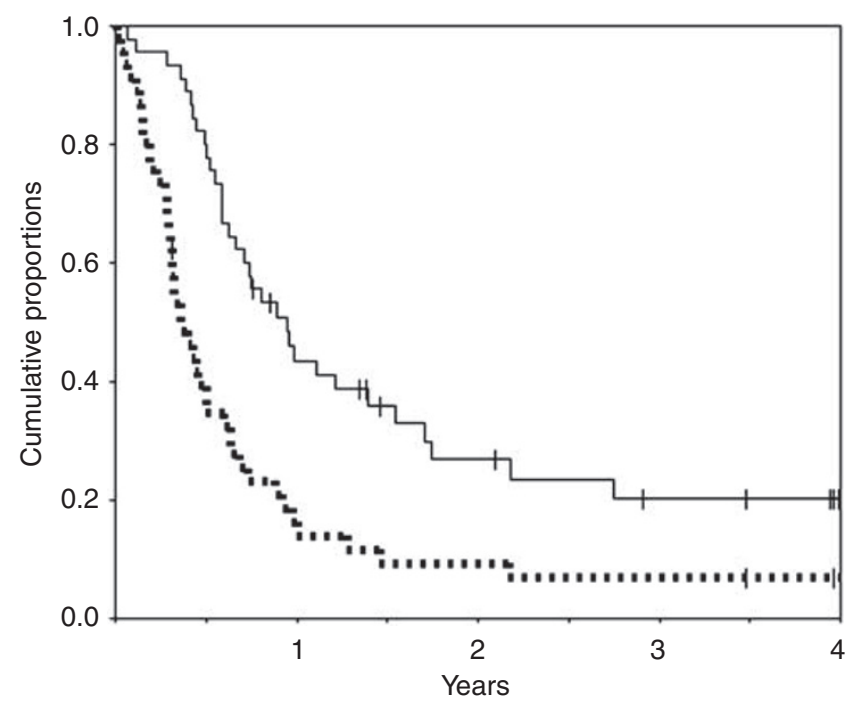

Figure I Kaplan-Meier analysis to determine the time to progression (dotted line) and overall survival (solid line).

months (Table 4). In two of these trials conducted to evaluate the activity of first-line platinum-based combination chemotherapy, the treatment regimen included irinotecan (Culine et al, 2003; Briasoulis et al, 2008a). According to one, the combination of irinotecan plus cisplatin yielded an objective response rate of $38 \%$ and median OS of 6 months (Culine et al, 2003). In another study limited to poor-prognosis patients, irinotecan plus oxaliplatin yielded an objective response rate of $13 \%$ and median survival time of 9.5 months, with $40 \%$ of the patients still alive at 1 year (Briasoulis et al, 2008a). The patient background, especially the prognostic characteristics, may have an influence on the treatment outcome. Two-thirds of the patients in this study were prognostically good-risk patients, with a low percentage of patients having liver metastasis and a large percentage of patients with the disease extent being limited to the lymph nodes; in contrast, in most of the recently published series, the majority of the patients were prognostically poor-risk patients and/or had liver metastasis. Therefore, potential bias would make a reliable comparison of the results of the present and previous studies difficult.

Interestingly, the Kaplan-Meier analysis in this study revealed a 2 -year survival rate of $27 \%$, with some patients even showing longterm survival (Figure 1). The results of chemotherapy in a total of 1515 patients enrolled in 45 trials including 10 patients or more conducted between 1964 and 2002 showed that survival of the patients beyond 2 years was rare and that there were no cases of disease-free survival beyond 3 years (Pavlidis et al, 2003; Greco and Hainsworth, 2008). However, more recent studies have reported long-term survival in a small percentage of patients (Table 4). Long-term follow-up of the 396 patients enrolled in the five most recent studies revealed 1-, 2-, 3-, 5-, 8- and 10-year survival rates of $38,19,12,11,8$ and $8 \%$ (Greco and Hainsworth, 2008). Although the reasons for the recent increase in long-term survival are uncertain, it is noteworthy that long-term survival was obtained with the combination of platinum agents and new agents.

The emergence of new non-platinum agents after 1995, including taxanes, gemcitabine, vinorelbine and irinotecan, has enabled the development of platinum-based combination chemotherapy for patients with CUP (Pavlidis et al, 2003). However, no definitive conclusions have been reached, because there is still no evidence based on randomised clinical trials to prove the superiority of the aforementioned combination chemotherapies over single-agent platinum therapy. In addition,
Table 3 Toxicity profiles (frequency $>$ 10\%)

\begin{tabular}{lccc}
\hline Profile & $\begin{array}{c}\text { Frequency } \\
\text { (\%) }\end{array}$ & $\begin{array}{c}\text { No. of } \\
\text { grade 3 (\%) }\end{array}$ & $\begin{array}{c}\text { No. of } \\
\text { grade 4 (\%) }\end{array}$ \\
\hline $\begin{array}{l}\text { Haematologic toxicity } \\
\text { Leukopaenia }\end{array}$ & 75.6 & $6(13.3)$ & $4(8)$ \\
Neutropaenia & 80 & $6(13.3)$ & $9(20)$ \\
Anaemia & 93.3 & $8(17.8)$ & $3(6.7)$ \\
Thrombocytopaenia & 68.9 & $7(15.6)$ & $2(4.4)$ \\
Non-haematologic toxicity & & & \\
Fatigue & 60 & $0(0)$ & $0(0)$ \\
Appetite loss & 46.7 & $0(0)$ & $0(0)$ \\
Nausea & 82.2 & $1(2.2)$ & $0(0)$ \\
Vomiting & 26.7 & $1(2.2)$ & $0(0)$ \\
Diarrhoea & 57.8 & $4(8)$ & $0(0)$ \\
Constipation & 42.2 & $0(0)$ & $0(0)$ \\
Skin rash & 20 & $0(0)$ & $0(0)$ \\
Febrile neutropaenia & 13.3 & $5(\mid 1.1)$ & $1(2.2)$ \\
\hline
\end{tabular}

the clinical benefits and risks of doublet and triplet combination chemotherapies are still uncertain. An attempt was made by European investigators to compare the effect of single-agent cisplatin with that of combined therapy with gemcitabine plus cisplatin on survival in good-risk patients with CUP. Although the results of this prospective trial were expected to clarify the role of combination chemotherapy in good-risk patients with CUP, the trial was stopped due to insufficient accrual, and the result showed a non-significantly higher survival with gemcitabine plus cisplatin as compared to that with cisplatin alone (Gross-Goupil et al, 2008).

Recently, standard chemotherapeutic regimens with or without molecular-targeting agents have been established for many cancers. Thus, there is a great demand to optimise the chemotherapeutic regimen for each patient with CUP. The approach based on the genomic characteristics may come to represent one of the breakthroughs in the proper use of chemotherapies tailored to individual patients.

In addition, the advances in the development of many molecular-targeted agents provide opportunities to explore various new combination therapies containing both cytotoxic and molecular-targeted agents for patients with CUP. Several studies have demonstrated the immunohistochemical expression of relevant molecular targets at high frequencies in tissue specimens (Massard et al, 2007). A phase II trial of bevacizumab plus erlotinib revealed substantial activity of this combination in patients treated previously or patients who had not received treatment because of the presence of poor-prognostic features (Hainsworth et al, 2007). In a preliminary study, treatment with paclitaxel plus carboplatin used in combination with bevacizumab plus erlotinib yielded an objective response rate of $48 \%(N=19$ out of 40) and was well tolerated as first-line chemotherapy for patients with CUP (Greco et al, 2008). After first-line platinumbased combination chemotherapy, the approach of empiric second-line chemotherapy has shown little promise, with extremely low response rates (Hainsworth et al, 2001, 2005). Therefore, tailor-made first-line chemotherapy by genomic typing or addition of molecular-targeted drugs may be important in the treatment of CUP, which includes heterogeneous cancers, rather than the development of second-line chemotherapy.

In this study, the most frequently encountered toxicity was haematological toxicity and some patients needed blood transfusion or dose reduction of carboplatin. The dose delivery was fairly smooth in the chemotherapy-naive patients with CUP as compared with that in our earlier phase I study of combined irinotecan plus carboplatin in patients with heavily treated ovarian cancer (Yonemori et al, 2005). Among the advantages of this regimen are 
Table 4 Clinical trials of first-line regimens containing platinum agents reported in the literature from 2000

\begin{tabular}{|c|c|c|c|c|c|c|c|}
\hline Group & Reference & Regimen & $\mathbf{N}$ & $\mathbf{R R}$ & MST (m) & I year ${ }^{a}$ & 2 year $^{b}$ \\
\hline & Voog et al (2000) & Cis $-E$ & 22 & $32 \%$ & 8.0 & NA & NA \\
\hline & Dowell et al (200I) & Carbo-E & 17 & $19 \%$ & 8.3 & $26 \%$ & NA \\
\hline & Saghatchian et al (2001) & $\mathrm{Cis}-\mathrm{E} \rightarrow \mathrm{Cis}-\mathrm{E}-\mathrm{B}-\mathrm{I}$ & 30 & $40 \%$ & 9.4 & NA & $28 \%$ \\
\hline & & Cis $-F$ & 18 & $44 \%$ & 16.1 & NA & $39 \%$ \\
\hline & & Cis-Ir & 40 & $38 \%$ & 6.0 & NA & NA \\
\hline & Park et al (2004) & Cis $-\mathrm{P}$ & 37 & $42 \%$ & 11.0 & $38 \%$ & $11 \%$ \\
\hline & El-Rayes et al (2005) & Carbo-P & 22 & $23 \%$ & 6.5 & $27 \%$ & NA \\
\hline & Pittman et al (2006) & Carbo-G & 51 & $30.5 \%$ & 7.8 & $26 \%$ & $12 \%$ \\
\hline & Briasoulis et al (2008a) & $O x-I r$ & 47 & $13 \%$ & 9.5 & $40 \%$ & NA \\
\hline & Pentheroudakis et al (2008) & Carbo-D & 47 & $32 \%$ & 16.2 & NA & NA \\
\hline & This study & Carbo-Ir & 45 & $41.9 \%$ & 12.2 & $44 \%$ & $27 \%$ \\
\hline & Balaña et al (2003) & Cis $-G-E$ & 30 & $36.6 \%$ & 7.2 & $26 \%$ & NA \\
\hline & Piga et al (2004) & Carbo-Dx-E & 102 & $26.5 \%$ & 9.0 & $35.2 \%$ & $18.1 \%$ \\
\hline & Greco et al (2004) & Carbo-P-E $\rightarrow \mathrm{G}-\mathrm{Ir}$ & 111 & $33 \%$ & 9.1 & $35 \%$ & $16 \%$ \\
\hline & Palmeri et al (2006) & $\mathrm{Cis}-\mathrm{G}-\mathrm{P}$ & 33 & $48.5 \%$ & 9.6 & NA & NA \\
\hline & & $\mathrm{Cis}-\mathrm{G}-\mathrm{V}$ & 33 & $42.3 \%$ & 13.6 & NA & NA \\
\hline & Schneider et al (2007) & Carb-G-Cape & 33 & $39.4 \%$ & 7.6 & $35.6 \%$ & $14.2 \%$ \\
\hline & Greco et al (2008) & Carbo-P-Bv-Er & 51 & $48 \%$ & 11.3 & NA & NA \\
\hline
\end{tabular}

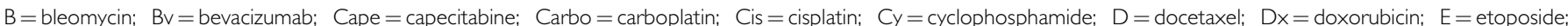
Ep = epirubicin; Er=erlotinib; F=5-FU; $G=$ gemcitabine; I= ifosfamide; Ir=irinotecan; $m=$ months; Mit = mitomycin C; MST=median survival time; NA = not available; $\mathrm{Ox}=$ oxaliplatin; $\mathrm{P}=$ paclitaxel; $\mathrm{RR}=$ response rate; $\mathrm{V}=$ vinorelbine. ${ }^{\mathrm{a}} \mathrm{I}$ year $=1$-year survival rate. ${ }^{\mathrm{b}} 2$ year $=2$-year survival rate.

that it is easy to adjust the irinotecan dose during each chemotherapy cycle according to the individual toxicity profiles and to manage the chemotherapy on an outpatient basis without prophylactic use of granulocyte-stimulating factor or erythropoietin.

In conclusion, combined irinotecan plus carboplatin chemotherapy appears to exert satisfactory activity and to be reasonably well tolerated in patients with CUP. Many conventional chemotherapies have been reported as the community standard of care for patients with CUP. This regimen was moderately well tolerated and may become established as one of the treatment options in patients with a good PS.

\section{REFERENCES}

Balaña C, Manzano JL, Moreno I, Cirauqui B, Abad A, Font A, Mate JL, Rosell R (2003) A phase II study of cisplatin, etoposide and gemcitabine in an unfavourable group of patients with carcinoma of unknown primary site. Ann Oncol 4: 1425-1429

Briasoulis E, Fountzilas G, Bamias A, Dimopoulis MA, Xiros N, Aravantinos G, Samantas E, Kalofonos H, Makatsoris T, Mylonakis N, Papakostas P, Skarlos D, Varthalitis I, Pavlidis N (2008a) Multicenter phase II trial of irinotecan plus oxaliplatin in patients with poor-prognosis cancer of unknown primary: a Hellenic cooperative oncology group study. Cancer Chemother Pharmacol 62: 277-284

Briasoulis E, Kalofonos H, Bafaloukos D, Samantas E, Fountzilas G, Xiros N, Skarlos D, Christodoulou C, Kosmidis P, Pavlidis N (2000) Carboplatin plus paclitaxel in unknown primary carcinoma; a phase II Hellenic Cooperative Oncology Group Study. J Clin Oncol 18: 3101 - 3107

Briasoulis E, Pavlidis N, Felip E (2008b) Cancers of unknown primary site: ESMO clinical recommendation for diagnosis, treatment and follow-up. Ann Oncol 19(Suppl 2): ii106-ii107

\section{ACKNOWLEDGEMENTS}

We thank Noboru Yamamoto, Yasuhiro Shimada and Eriko Nakano (National Cancer Center Hospital) for their assistance in the conduct of this study.

\section{Conflict of interest}

Katsumata N: Honoraria (Sanofi-aventis, Pfizer, Nippon Kayaku, Kyowa Hakko Kogyo, Zeneca). His family members have no financial interest or conflict of interest in relation to this study. None of the authors or their immediate family members have any financial interest or conflict of interest in relation to this study.

Calvert AH, Newell DR, Gumbrell LA, O’Reilly S, Burnell M, Boxall FE, Siddik ZH, Judson IR, Gore ME, Wiltshaw E (1989) Carboplatin dosage: prospective evaluation of a simple formula based on renal function. J Clin Oncol 7: $1748-1756$

Cockcroft DW, Gault MH (1976) Prediction of creatine clearance from serum creatinine. Nephron 16: $31-41$

Culine S, Fabbro M, Ychou M, Romieu G, Cupissol D, Pinguet F (2002b) Alternative bimonthly cycles of doxorubicin, cyclophosphamide, and etoposide, cisplatin with hematopoietic growth factor support in patients with carcinoma of unknown primary site. Cancer 94: 840-846

Culine S, Kramar A, Saghatchian M, Bugat R, Lesimple T, Lortholary A, Merrouche Y, Laplanche A, Fizazi K (2002a) Development and validation of a prognostic model to predict the length of survival in patients with carcinomas of an unknown primary site. J Clin Oncol 20: $4679-4683$

Culine S, Lortholary A, Voigt JJ, Bugat R, Théodore C, Priou F, Kaminsky MC, Lesimple T, Pivot X, Coudert B, Douillard JY, Merrouche Y, 
Allouache J, Goupil A, Négrier S, Viala J, Petrow P, Bouzy J, Laplanche A, Fizazi K (2003) Cisplatin in combination with either gemcitabine or irinotecan in carcinomas of unknown primary site: results of a randomized phase II study-trial for the French Study Group on Carcinomas of Unknown Primary (GEFCAPI 01). J Clin Oncol 21: $3479-3482$

Dowell JE, Garrett AM, Shyr Y, Johonson DH, Hande KR (2001) A randomized phase Ii trial in patients with carcinoma of an unknown primary site. Cancer 91: 592-597

El-Rayes BF, Shields AF, Zalupski M, Heilbrun LK, Jain V, Terry D, Ferris AM, Philip PA (2005) A phase II study of carboplatin and paclitaxel in adenocarcinoma of unknown primary. Am J Clin Oncol 28: $152-156$

Greco FA, Burris III HA, Erland JB, Gray JR, Kalman LA, Schreeder MT, Hainsworth JD (2000b) Carcinoma of unknown primary site. Cancer 89: $2655-2660$

Greco FA, Burris III HA, Litchy S, Barton JH, Bradof JE, Richards P, Scullin Jr DC, Erland JB, Morrissey LH, Hainsworth JD (2002) Gemcitabine, carboplatin, and paclitaxel for patients with carcinoma of unknown primary site: a Minnie Pearl Cancer Research Network study. J Clin Oncol 20: $1651-1656$

Greco FA, Burris III HA, Spigel DR, Thompson DS, Waterhouse DM, Hanson S, Vazquez ER, Hainsworth JD (2008) Paclitaxel/carboplatin plus bevacizumab/erlotinib as first-line treatment for patients with carcinoma of unknown primary site. J Clin Oncol 26(15S): 239s

Greco FA, Erland JB, Morrissey LH, Burris III HA, Hermann RC, Steis R, Thompson D, Gray J, Hainsworth JD (2000a) Carcinoma of unknown primary site: phase II trials with docetaxel plus cisplatin or carboplatin. Ann Oncol 11: 211-215

Greco FA, Hainsworth JD (2008) Cancer of unknown primary site. In Cancer, Principle and Practice of Oncology, De Vita VT, Lawrence TS, Rosenberg SA (eds), pp 2363-2387. Lippincott Williams and Wilkins: Philadelphia

Greco FA, Rodriguez GI, Shaffer DW, Hermann R, Litchy S, Yardley DA, Burris III HA, Morrissey LH, Erland JB, Hainsworth JD (2004) Carcinoma of unknown primary site: sequential treatment with paclitaxel/carboplatin/etoposide and gemcitabine/irinotecan: a Minnie Pearl Cancer Research Network II phase trial. Oncologist 9: $644-652$

Gross-Goupil M, Fourcade A, Blot A, Penel N, Negrier S, Culine S, Moerrouche Y, Bouzy J, Laplanche A, Fizazi K (2008) A randomized trial of cisplatin with or without gemcitabine in patients with carcinoma of an unknown primary and without poor prognostic factors: results of the GEFCAPI02 trial. Ann Oncol 19(Suppl 8): vii248

Guardiola E, Pivot X, Tchicknavorian X, Magne N, Otto J, Thyss A, Schnider M (2001) Combination of cisplatin-doxorubicin-cyclophosphamide in adenocarcinoma of unknown primary site: a phase II trial. Am J Clin Oncol 24: 372-375

Hainsworth JD, Burris III HA, Calvert SW, Willcutt NT, Scullin Jr DC, Bramham J, Greco FA (2001) Gemcitabine in the second-line therapy of patients with carcinoma of unknown primary site: a II phase trial of the Minnie pearl cancer research network. Cancer Invest 19: $335-339$

Hainsworth JD, Spigel DR, Farley C, Thompson DS, Shipley DL, Greco FA (2007) Phase II trial of bevacizumab and erlotinib in carcinomas of unknown primary site: the Minnie pearl cancer research network. J Clin Oncol 25: $1747-1752$

Hainsworth JD, Spigel DR, Raefsky EL, Kuzur ME, Yost K, Kommor M, Litchy S, Greco FA (2005) Combination chemotherapy with gemcitabine and irinotecan in patients with previously treated carcinoma of unknown primary site: a Minnie pearl cancer research network phase II trial. Cancer 104: 1992-1997

Kano Y, Akutsu M, Suzuki K, Yoshida M (1993) Effects of carboplatin in combination with other anticancer agents on human leukemia cell lines. Leukemia Res 17: 113-119

Kano Y, Suzuki K, Akutsu M, Suda K, Inoue Y, Yoshida M, Sakamoto S, Miura Y (1992) Effects of CPT-11 in combination with other anticancer agents in culture. Int J Cancer 50: 604-610

Macdonald AG, Nicolson MC, Samuel LM, Hutcheon AW, Ahmed FY (2002) A phase II study of mitomycin C, cisplatin and continuous infusion 5-Fluorouracil in the treatment of patients with carcinoma of unknown primary site. Br J Cancer 86: 1238-1248
Massard C, Voigt JJ, Laplanche A, Culine S, Lortholary A, Bugat R, Theodore C, Priou F, Kaminsky MC, Lesimple T, Pivot X, Coudert B, Douillard JY, Merrouche Y, Fizazi K (2007) Carcinoma of an unknown primary: are EGF receptor, Her-2/neu, and c-Kit tyrosine kinases potential targets for therapy? Br J Cancer 97: 857-861

Misawa T, Kikkawa F, Maeda O, Obata NH, Higashide K, Suganuma N, Tomoda Y (1995) Establishment and characterization of acquired resistance to platinum anticancer drugs in human ovarian carcinoma cells. Jpn J Cancer Res 86: 88-94

Mukai H, Watanabe T, Ando M, Katsumata N (2003) Unknown primary carcinoma: a feasibility assessment of combination chemotherapy with cisplatin and docetaxel. Int J Clin Oncol 8: 23-25

Palmeri S, Lorusso V, Palmeri L, Vaglica M, Porta C, Nortilli R, Ferraú F, Comella G, Massidda B, Danova M (2006) Cisplatin and gemcitabine with either vinorelbine or paclitaxel in the treatment of carcinomas of unknown primary site : results of an Italian multicenter, randomized, phase II study. Cancer 107: 2898-2905

Park YH, Ryoo BY, Choi SJ, Yang SH, Kim HT (2004) A phase II study of paclitaxel plus cisplatin chemotherapy in an unfavourable group of patients with cancer of unknown primary site. Jpn J Clin Oncol 34: 681 -685

Parnis FX, Olver IN, Kotasek D, Norman J, Taylor A, Russell J, Patterson K, Keefe D, Marafioti T (2000) Phase II study of epirubicin, cisplatin and continuous infusion 5-fluorouracil for carcinoma of unknown primary site. Ann Oncol 11: 883-884

Pavlidis N, Briasoulis E, Hainsworth J, Greco FA (2003) Diagnostic and therapeutic management of cancer of an unknown primary. Eur J Cancer 39: $1990-2005$

Pentheroudakis G, Briasoulis E, Kalofonos HP, Fountzilas G, Economopoulos T, Samelis G, Koutras A, Karina M, Xiros N, Samantas E, Bamias A, Pavlidis N (2008) Docetaxel and carboplatin combination chemotherapy as outpatient palliative therapy in carcinoma of unknown primary: a multicenter Hellenic cooperative oncology group phase II study. Acta Oncologica 47: $1148-1155$

Piga A, Nortilli R, Cetto GL, Cardarelli N, Luzi Fedeli S, Fiorentini G, D’Aprile M, Giorgi F, Parziale AP, Contu A, Montironi R, Gesuita R, Carle F, Cellerino R (2004) Carboplatin, doxorubicin and etoposide in the treatment of tumours of unknown primary site. $\mathrm{Br} J$ Cancer 90: $1898-1904$

Pittman KB, Olver IN, Koczwara B, Kotasek D, Patterson WK, Keefe DM, Karapetis CS, Parnis FX, Moldovan S, Yeend SJ, Price TJ (2006) Gemcitabine and carboplatin in carcinoma of unknown primary site: a phase 2 Adelaide Cancer Trials and Education Collaborative study. $\mathrm{Br} \mathrm{J}$ Cancer 95: 1309-1313

Saghatchian M, Fizazi K, Borel C, Ducreux M, Ruffie P, Le Chevalier T, Theodore C (2001) Carcinoma of an unknown primary site: a chemotherapy strategy based on histological diffentiation-results of a prospective study. Ann Oncol 12: 535-540

Schneider BJ, El-Rayes B, Muler JH, Philip PA, Kalemkerian GP, Griffith KA, Zalupski MM (2007) Phase II trial of carboplatin, gemcitabine, and capecitabine in patients with carcinoma of unknown primary site. Cancer 110: 770 - 775

Therasse P, Arbuck SG, Eisenhauer EA, Wanders J, Kaplan RS, Rubinstein L, Verweij J, Van Glabbeke M, van Oosterom AT, Christian MC, Gwyther SG (2000) New guidelines to evaluate the response to treatment in solid tumors: European Organization for Research and Treatment of Cancer, National Cancer Institute of the United States, National Cancer Institute of Canada. J Natl Cancer Inst 92: 205-216

van der Gaast A, Verweij J, Planting AS, Hop WC, Stoter G (1996) Simple prognostic model to predict survival in patients with undifferentiated carcinoma of unknown primary site. J Clin Oncol 13: 1720-1725

Voog E, Merrouche Y, Trillet-Lenoir V, Lasset C, Peaud PY, Rebattu P, Negrier S (2000) Multicentric phase II study of cisplatin and etoposide in patients with metastatic carcinoma of unknown primary. Am J Clin Oncol 23: 614-616

Yakushiji S, Ando M, Yonemori K, Kohno T, Shimizu C, Katsumata N, Fujiwara Y (2006) Cancer of unknown primary site: review of consecutive cases at the National Cancer Center Hospital of Japan. Int J Clin Oncol 11: 421-425

Yonemori K, Katsumata N, Yamamoto N, Kasamatsu T, Yamada T, Tsunematsu R, Fujiwara Y (2005) A phase I study and pharmacologic evaluation of irinotecan and carboplatin for patients with advanced ovarian carcinoma who previously received platinum-containing chemotherapy. Cancer 104: 1204-1212 